Rivka Feldhay \& F. Jamil Ragep (eds.). Before Copernicus: The Cultures and Contexts of Scientific Learning in the Fifteenth Century. Montreal: McGill-Queen's University Press, 2017. 368 pages. ISBN: 9780773550094.

\title{
Scott Trigg*
}

Why did Nicholas Copernicus (d. 1543) adopt heliocentrism? This question has captured the attention of laypeople and historians of science alike, and while decades of research have done much to dispel the notion of a lone genius who sparked a scientific revolution, his intellectual context in many ways remains simultaneously controversial and poorly understood. What precisely was the problem or set of questions that Copernicus had attempted to answer? What were the tools at his disposal, whether mathematical or metaphysical, and to what extent and in what form did ideas from Arabic, Hebrew, and other languages reach him? The editors of Before Copernicus, dissatisfied with recent works that tend to "reduce the 'Copernican question' to one of finding the univocal explanation that somehow supersedes all others" and lean in a Eurocentric direction, organized a series of workshops and multifaceted discussions on $15^{\text {th }} \mathrm{c}$. astronomy (5). Two themes unite the resulting volume: astronomy as an evolving discipline in the $15^{\text {th }} \mathrm{c}$. and the circulation of knowledge within Europe and across the Mediterranean world. The individual chapters go beyond technical analysis to focus on astronomical knowledge as an evolving set of mathematical, natural philosophical, and epistemological practices circulating across disciplines, languages, and cultures in the period leading up to Copernicus' Commentariolus, the earliest presentation of his new cosmology.

The first section addresses the European social and political contexts in which Copernicus studied and worked, prompting the reader to reflect on forces that promoted or hindered the circulation of knowledge in this period. In his chapter "What did It Mean to Live in the Long Fifteenth Century?", Christopher Celenza identifies several factors that shaped the lives and thoughts of $15^{\text {th }} \mathrm{c}$. intellectuals

* Dr., Society of Fellows in the Humanities, The University of Hong Kong. Correspondence: strigg@hku.hk. 
such as Copernicus, particularly the role of travel and the experience of different cultural traditions in the pursuit of patronage, as well as the contemporary practices of reading and writing, which had taken on a collaborative, mediated nature. For Celenza, these factors "make it likely that [Copernicus] may well have come across a theory like the 'Ṭūsi-couple' without feeling the characteristically modern need to record precisely where, when, and in what format he encountered it" (28). Juxtaposed with this picture of knowledge in motion within Latin humanist scholarly communities, Nancy Bisaha's chapter "European Cross-Cultural Contexts before Copernicus" discusses the contrasting portrayals of Europe and Asia in the writings of Pope Pius II (d. 1464), particularly his hostile presentation of the Turks after the fall of Constantinople and the ways in which changing perceptions of "the other" may have influenced how ideas were received. Humanist rhetoric contributed to a "cultural discourse of European superiority" that suggests near-contemporary Islamic influence on Copernicus's ideas may have been intentionally or unconsciously obscured, as opposed to the open acknowledgement of earlier Islamic authorities such as Avicenna (d. 428/1037) and Averroes (d. 595/1198) (41).

The volume's second section covers specific topics in Copernicus's intellectual and scientific context with a shared focus on the evolving disciplinary nature of astronomy and its epistemic status. Edith Dudley Sylla's chapter "The Status of Astronomy as a Science in Fifteenth-Century Cracow: Ibn al-Haytham, Peurbach, and Copernicus" draws on Peurbach's (d. 1461) Theorica novae planetarum along with contemporary discussions of the relationship between mathematics and Aristotelian physics that had been circulating at the time of Copernicus' student days in Crakow to explore how conceptions of the tools and methods of astronomy as a scientific discipline may have shaped Copernicus's earliest work. Sylla situates the Commentariolus within a tradition of research in which the mathematical hypotheses and physical configurations of real orbs were acknowledged as not being fully consistent, a tradition she traces back to Ibn al-Haytham's (d. circa 432/1040) Arabic work On the Configuration of the World, although perhaps claims for Ibn al-Haytham's influence on the development of solid-orb modeling in the Latin tradition no longer require defending. Next is a discussion of the progressive or via moderni form of Aristotelianism prevalent in the $14^{\text {th }}$ and $15^{\text {th }} \mathrm{c}$. in which the principles of astronomy as a scientific discipline were derived from experience and could therefore be changed on the basis of additional experience rather than being given a priori. Sylla draws on a variety of Latin Aristotelian texts and commentaries to set the stage for an examination of the astronomical works of John of Głogów (d. 1507) and Albert of Brudzewo (d. 1497) that Copernicus likely would have encountered in Crakow (either as lectures or in manuscript form). On the basis of these texts, Copernicus would have learned 
that the physical side of astronomy was in need of reform and that "an alternate and more satisfactory theorica of the planets" was a desideratum (78).

In contrast to earlier scholarship presenting Regiomontanus (d. 1476) as a highly skilled yet "traditionalist" Ptolemaic astronomer, Michael Shank's chapter "Regiomontanus and Astronomical Controversy in the Background of Copernicus" argues that Regiomontanus had been a reformer who reframed outstanding questions in mathematical astronomy, an interpretation with significant implications for the development of Copernicus's thought on the relationship between observational evidence and physical astronomy. Shank provides a vivid account of the personal and political contexts for several of Regiomontanus' works, highlighting the role personal connections and rivalries played in the development of astronomy in the late $15^{\text {th }}$ c. Historians have long acknowledged Copernicus's extensive reliance on Regiomontanus's Epitome of the Almagest, which provided the geometrical foundation for the transformation to a heliocentric system. To better understand the context of the Epitome, much of Shank's discussion derives from his study of the Defense of Theon, an unpublished yet crucial text that had emerged out of Regiomontanus's deep interest in astronomical reform as well as his involvement in a pitched controversy about the Almagest on behalf of his patron, Cardinal Bessarion (d. 1472). Written as a polemical attack on rival astronomer George of Trebizond (d. 1484), the Defense of Theon was a mathematically rigorous study of problems in astronomical theory that reveals much about Regiomontanus' metaphysical and methodological commitments, including his skepticism about the physical adequacy of Ptolemy's models and the continuing importance of the quest for a homocentric astronomy. In connection with Copernicus, Shank notably argues that the Defense of Theon helps clarify the mystery surrounding Regiomontanus' "correction" in the Epitome of Ptolemy's remarks in Book XII of the Almagest on the equivalence of the eccentric and epicyclic hypotheses for the problem of retrograde planetary motion, which provided the geometrical foundation for Copernicus's new system. Ptolemy had curiously stated that the eccentric hypothesis was not viable for the inferior planets, but in the Epitome, Regiomontanus proved the equivalence for all planets without commenting on Ptolemy's position. F. Jamil Ragep has suggested this represents a borrowing from the contemporary Islamic astronomer 'Alī Qushjī (d. 879/1474), who criticized Ptolemy on this point. ${ }^{1}$ However, Shank contends that the polemic against George of Trebizond in the Defense of Theon reveals Regiomontanus could 
not believe Ptolemy truly had meant equivalence was mathematically impossible for the inferior planets, with Regiomontanus instead attacking George for his "failure to understand" Ptolemy (103).

Regiomontanus also appears in Raz Chen-Morris \& Rivka Feldhay's chapter "Framing the Appearances in the Fifteenth Century: Alberti, Cusa, Regiomontanus, and Copernicus" on "appearances" and the relationship between attempts to reconcile the visible with the conceptual/visualized in $15^{\text {th }} \mathrm{c}$. art, theology, and astronomy. The majority of their analysis centers on the work of Leon Battista Alberti (d. 1472) and Nicholas of Cusa (d. 1464), both of whom promoted systems of using mathematics for viewing things hidden in nature. For Alberti, this was the theory of artificial perspective in art, wherein the artist strove to use mathematics to recreate the hidden order of nature by deriving data from observations of physical bodies. Chen-Morris \& Feldhay find a similar desire to look beyond appearances in Cusa's theological works, with his use of mathematics and diagrams for aiding in theological speculations. For Cusa, a mathematical analysis or "intellectual vision" would help uncover nature's divine meaning, in contrast to the allegorical reading of nature by earlier theologians. Chen-Morris \& Feldhay suggest that a new questioning of the stability of appearances and the use of mathematics in uncovering a hidden order in nature may have helped predispose Copernicus to accept a moving Earth as the hidden truth behind the appearance of its stability. And yet one wonders to what extent this notion of seeking a hidden mathematical order in nature was really new? Cusa may have been doing innovative and mathematically-inspired theological work, but astronomers and philosophers had been searching for mathematical order underlying apparent irregularity and disorder since Antiquity. It is not clear that either of what Alberti or Cusa were doing was sufficient to inspire Copernicus toward accepting a moving Earth. As Chen-Morris \& Feldhay note, expert practitioners of mathematics such as Regiomontanus and Toscanelli (d. 1482) balanced their respect for Cusa as a scholar and Church official with a somewhat-guarded dismissal of his mathematical work as obscure if not incompetent.

The third and final section expands the focus to the multicultural context and the likely influences on Copernicus from Islamic and Jewish sources. Sally Ragep's chapter "Fifteenth-Century Astronomy in the Islamic World" draws on a preliminary survey of approximately 500 astronomical texts to critique several of the common narratives of the history of Islamic science. She argues that the range of texts produced in the $15^{\text {th }}$ c., along with the numbers of people studying and teaching them (whether at madrasas or elsewhere), indicate that historians should not accept the claim that science or science education in this period had been a series of discrete episodes. She also notes that, in responding to debates on the exclusion of science from the 
madrasas or religious antagonism toward the rational sciences, many scholars have turned to a focus on individuals and networks. Although praising their results and insights, she suggests that "such an emphasis on the local can result in missing the big picture," namely the role of scientific traditions and the many continuities that sustained the development of Islamic astronomy (155). She points to the valorization of the so-called Marāgha school that pushed the formative role scholars had had in the preceding centuries into the background, the variety of Islamic institutions where we now know science was studied, and pedagogical reasons for the increasing prevalence of texts that contain illustrations and diagrams, particularly in $15^{\text {th }}$-century Central Asia and the Ottoman Empire. Ragep suggests that visual evidence ought to be considered more seriously as a force for spreading ideas and that the existence of an established scientific tradition in the Islamic world may been a factor inhibiting the emergence of alternative theories, in contrast with the "less rigid" scientific context surrounding Copernicus (158).

F. Jamil Ragep provides a critical review of recent scholarship on the Ṭūsĩ couple and debates over Islamic influence on Copernicus in his chapter "From Tūn to Torun: The Twists and Turns of the Tūisi-Couple." Historical debates tend to overlook the fact that multiple versions of the Țùsi couple have been found that were used for different purposes. For Ragep, this confusion in the literature has interfered with efforts to trace the movement of ideas and mathematical theories. Ragep meticulously documents the evolution and application of different versions of the Țūsi couple, some appearing in rectilinear and others in curvilinear form, each of which were at times produced out of circles or spheres while Țūsī worked over the course of 25 years to solve multiple problems in Ptolemaic astronomy. As Ragep notes, the upshot of this detailed study is that "such devices and models take time to evolve and be perfected. A sudden appearance of a complete and perfected theory or model should make us wary of claims of no transmission or influence" (168). Ragep then turns to the appearances of the Tùis couple in Latin Europe from the $14^{\text {th }}$ to $16^{\text {th }}$ centuries and recent evidence for transmission of non-Ptolemaic models via a number of potential routes as opposed to "parallel development." These include material from Persian to Greek via Byzantium, from Arabic to Latin via Spain, and in Hebrew via Jewish intermediaries in Italy. More broadly, Ragep critiques the Eurocentric historiographic fallacy that intercultural transmission largely ended after the $12^{\text {th }}$-century translation movement from Arabic to Latin and argues the "sustained, historically coherent development of alternative models" in the Islamic world contrasts sharply with "the Latin West's ad-hoc, episodic, and decontextualized 'parallel' attempts" to solve problems in Ptolemaic astronomy, suggesting that the Ṭūsī couple "had become commonplace" by the time of Copernicus (196-97). 
In the final chapter "Jews as Scientific Intermediaries in the European Renaissance," Robert Morrison presents exciting recent discoveries on Jewish scholars who facilitated connections between astronomers around the Mediterranean, many of whom shared an interest in homocentric modeling as an alternative to Ptolemaic models. He documents the work of several Jewish travelers and scholars, particularly Moses ben Judah Galeano (d. post-1542), who were simultaneously familiar with current developments in theoretical astronomy in the Islamic world and known to have direct contact with Christian astronomers and scholars in Italy as well as Constantinople/Istanbul under both the Byzantines and Ottomans. Morrison draws on his earlier study of the Andalusian astronomer Ibn Nahmias (fl. circa 1400), whose use of a double-circle mathematical device to account for variations in motion along the surface of a sphere represented an improvement over similar efforts by Regiomontanus, and which had been transmitted to Padua via the writings of Galeano. As with much of the evidence connecting Copernicus to developments in Islamic and even Jewish astronomy, Morrison's examples are perhaps more circumstantial than conclusive when taken individually, but their combined impact is quite convincing. Thus, as Morrison concludes with respect to Renaissance Europe, the Byzantine Empire, and the Ottoman Empire, "contact between astronomers on matters of theoretical astronomy is more plausible than a presumption of no contact" (214).

This stimulating collection of essays presents a rich picture of the intellectual milieu out of which Copernicus had developed his earliest version of the heliocentric system and should be of great interest to a wide range of historians beyond specialists in Renaissance astronomy. Taken together, the essays underline the continuing need for comparative studies of the intellectual and cultural contexts of science around the Mediterranean. They also suggest that future research, particularly that focuses on lesser-known individuals or unedited sources, has the potential to significantly revise existing narratives about the development of early modern science. 